\title{
Medical Image of the Week: Type A Aortic Dissection Extending Into Main Coronary Artery
}

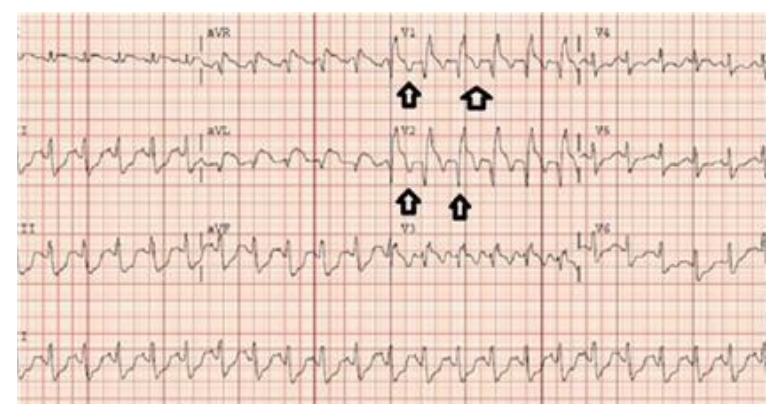

Figure 1. Electrocardiogram at presentation showing ST segment elevation in anterior leads (arrows).

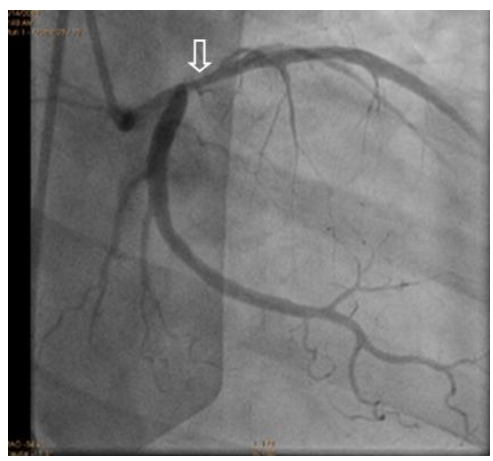

Figure 2. Coronary angiogram showing RAO caudal view of left main coronary artery after contrast injection with the smooth proximal linear irregularity suspicious for dissection flap into the left anterior descending artery (arrow).

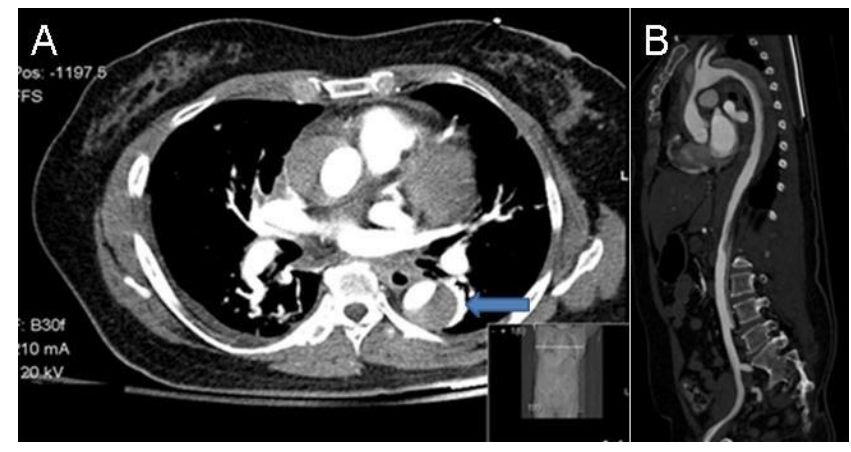

Figure 3. Panel A: Computed tomography angiogram transverse view showing true lumen and false lumen of both ascending and descending aorta (arrow). Panel B: Computed tomography angiogram sagittal view showing dissection from root into abdominal aorta. 
A 58-year-old woman with no significant past medical history, presented to the emergency department with complains of sudden onset, severe, non-radiating epigastric pain associated with nausea and vomiting. An electrocardiogram (EKG) done in emergency department showed ST segment elevation in the anterior leads (Figure 1). Blood pressure at presentation was 141/79, and she had symmetrical bilateral pulses of the upper extremities, no diastolic murmur, and no neurologic deficit. The patient was taken to catherization laboratory, for ST segment elevated myocardial infarction (STEMI). She was found have aortic dissection extending to the left main coronary artery (Figure 2). Cardiothoracic surgery was called immediately. Computed tomography angiogram (CTA) of the thoracic and abdominal aorta revealed Debakey type 1 aortic dissection. (Figure 3). The patient was taken to the operating room. Unfortunately, the patient suffered pulseless electrical activity (PEA) arrest during anesthesia induction from which she could not be revived.

Aortic dissection is a critical compromise in the lining of the main arterial outflow from the heart (1). Two theories have been proposed to explain the pathogenesis. A tear in the tunica intima, of the aorta, leads to blood from the aortic lumen surging into the tunica media (2). In contrast, the second theory holds that the vasa vasorum in the more outer portions of the tunica media hemorrhage first and then cause the rupture of the tunica intima (2). The pressure of the pulsatile blood flow extends the dissection, typically in an anterograde fashion (2). Anatomically aortic dissection is classified as Debakey 1,2, and 3 and Stanford A and B (1). Rarely aortic dissections can also extend in a retrograde fashion to reach the coronary ostia (3). Signs of myocardial ischemia including ST segment changes, adversely affect survival outcomes in patients with type A aortic dissection extending to the coronary arteries (4).

Ali Osama Malik MD¹, Oliver Abela MD², Chowdhury Ahsan MD², and Jimmy Diep MD² ${ }^{1}$ Department of Internal Medicine

${ }^{2}$ Department of Cardiovascular Medicine

University of Nevada School of Medicine

Las Vegas, NV USA

\section{References}

1. Golledge J, Eagle KA. Acute aortic dissection. Lancet. 2008 Jul 5;372(9632):55-66. [CrossRef] [PubMed]

2. Patel AY, Eagle KA, Vaishnava P. Acute type B aortic dissection: insights from the International Registry of Acute Aortic Dissection. Ann Cardiothorac Surg. 2014 Jul;3(4):368-74. [CrossRef] [PubMed]

3. Neri E, Toscano T, Papalia U, Frati G, Massetti M, Capannini G, et al. Proximal aortic dissection with coronary malperfusion: presentation, management, and outcome. J Thorac Cardiovasc Surg. 2001 Mar;121(3):552-60. [CrossRef] [PubMed]

4. Imoto K, Uchida K, Karube N, Yasutsune T, Cho T, Kimura K, et al. Risk analysis and improvement of strategies in patients who have acute type $A$ aortic dissection with coronary artery dissection. Eur J Cardiothorac Surg. Sep;44(3):419-24; discussion 24-5. [CrossRef] [PubMed] 